\title{
SHORT COMMMUNICATION \\ COVID-19 IN THE CZECH REPUBLIC 2020: PROBABLE TRANSMISSION OF THE CORONAVIRUS SARS-COV-2
}

\author{
Milan Tuček \\ Institute of Hygiene and Epidemiology, First Faculty of Medicine, Charles University, Prague, Czech Republic
}

\begin{abstract}
SUMMARY
Objectives: The aim of the study was to determine the probable places of coronavirus transmission in association with the work.

Methods: The work analysed data from the Information System of Infectious Diseases managed by the Institute of Health Information and Statistics of the Czech Republic in the period March-December 2020.

Results: 732,202 COVID-19 cases were officially confirmed, from them 64,587 (9\%) represented work-related disease, 184,384 cases (25\%) work-related contact, and 483,231 cases (66\%) out-of-work contact. There were identified 13 occupations with the highest incidence of COVID-19 in the observed period (42,072 cases), in descending order nurse, paramedic, teacher, machinist, clerk, social worker, physician, worker/agency worker, craftsman, policeman, manager, food worker, and miner; 150 cases of COVID-19 were recognized as an occupational disease in 2020, from them 148 cases in the health and social care economic activity sector.

Conclusion: The available data show probable exposures to an infectious agent (without proof of specific contact with the source of the infection), of which at least one third are related to work, so different relevant anti-epidemic measures in the workplace have considerable practical importance for epidemic control.
\end{abstract}

Key words: COVID-19, work-related disease, work-related contact, occupational disease, epidemic control

Address for correspondence: M. Tuček, Institute of Hygiene and Epidemiology, First Faculty of Medicine, Charles University, Studničkova 7 , 12800 Prague, Czech Republic. E-mail: milan.tucek@lf1.cuni.cz

https://doi.org/10.21101/cejph.a6963

\section{INTRODUCTION}

Coronavirus disease 2019 (COVID-19) is a communicable infectious disease caused by the coronavirus SARS-CoV-2, highly infectious agent transmitted from person to person. The COVID-19 pandemic is considered the most serious health threat since the global influenza epidemic (so-called Spanish influenza) in 1918-1920 caused by the H1N1 influenza A virus. On March 1, 2020, the first cases of COVID-19 in the Czech Republic were reported (1). In response to the unfavourable epidemiological situation, the government declared a so-called state of emergency in accordance with the constitutional law and adopted a number of measures, including restrictions on movement, closure of schools and restaurants, regulation of travel and entry of persons into the territory of the Czech Republic from abroad, possible postponement of occupational medical preventive examinations for the medical fitness assessment for work, the obligation to wear veils, the allocation of hospital beds, and others (2). While in the spring of 2020, due to restrictive anti-epidemic measures and their acceptance by the population, the course of the epidemic in the Czech Republic was very favourable, since autumn 2020 there have been significant daily increases in new cases of COVID-19, hospitalized patients, including severe cases in intensive care units, and people who have died of the infection. This change was caused by the release of restrictions in the summer and especially by the late reintroduction of restrictions in early autumn, influenced by pre-election political decisions, disrespect for expert recommendations and the rejection of restrictions by a certain part of the population. It should be added that government measures are still very inconsistent, permeated by numerous exceptions (industry versus services) and frequent illogical changes, which significantly contributed to the rejection of restrictions during the time of community spread of the infection, which leads to difficult or impossible capture contacts. While the industry has not been affected by all government restrictions, hotel and restaurant services have been affected very significantly, and trade has been partially affected (3).

\section{MATERIALS AND METHODS}

The work analysed data from the Information System of Infectious Diseases (Czech acronym ISIN) managed by the Institute of Health Information and Statistics of the Czech Republic (Czech acronym ÚZIS) in the period March-December 2020. The work- 
related disease was identified on the basis of the work environment and the probable causality with the occupational exposure. The work contact includes cases without a proven origin of the disease in the workplace. The last entity was group of COVID-19 cases without work contact. The author added data of COVID-19 cases officially recognized as occupational diseases in 2020 from the Registry of Occupational Diseases (National Institute of Public Health, Prague).

\section{RESULTS}

732,202 officially confirmed COVID-19 cases were reported in the period March-December 2020, from them 64,587 (9\%) cases were possible to classify as work-related disease. Work-related contact was recorded in 184,384 cases $(25 \%)$ and out-of-work contact in 483,231 cases (66\%). The incidence of COVID-19 cases in individual months of the year is shown in Figure 1. Thirteen occupations with the highest incidence of COVID-19 in the ob- served period are shown in Figure 2, in descending order: nurse, paramedic, teacher, machinist, clerk, social worker, physician, worker/agency worker, craftsman, policeman, manager, food worker, and miner; 150 cases of COVID-19 were recognized as an occupational disease in 2020, from them 148 cases in the health and social care economic activity sector (especially 62 nurses, 27 doctors, 27 paramedics, 16 other healthcare workers, 4 social workers). Among other branches of economic activity, COVID-19 was recognized in the banking specialist and singing teacher. In $23 \%$ of cases, the disease was described under influenza-like symptoms or inflammation of the upper respiratory tract, in 3 cases the disease caused pneumonia. In the remaining cases, the clinical symptoms of the disease were not reported (4).

\section{DISCUSSION}

The validity of the processed information depended on the level of reporting cases to the information system (ISIN). It is difficult

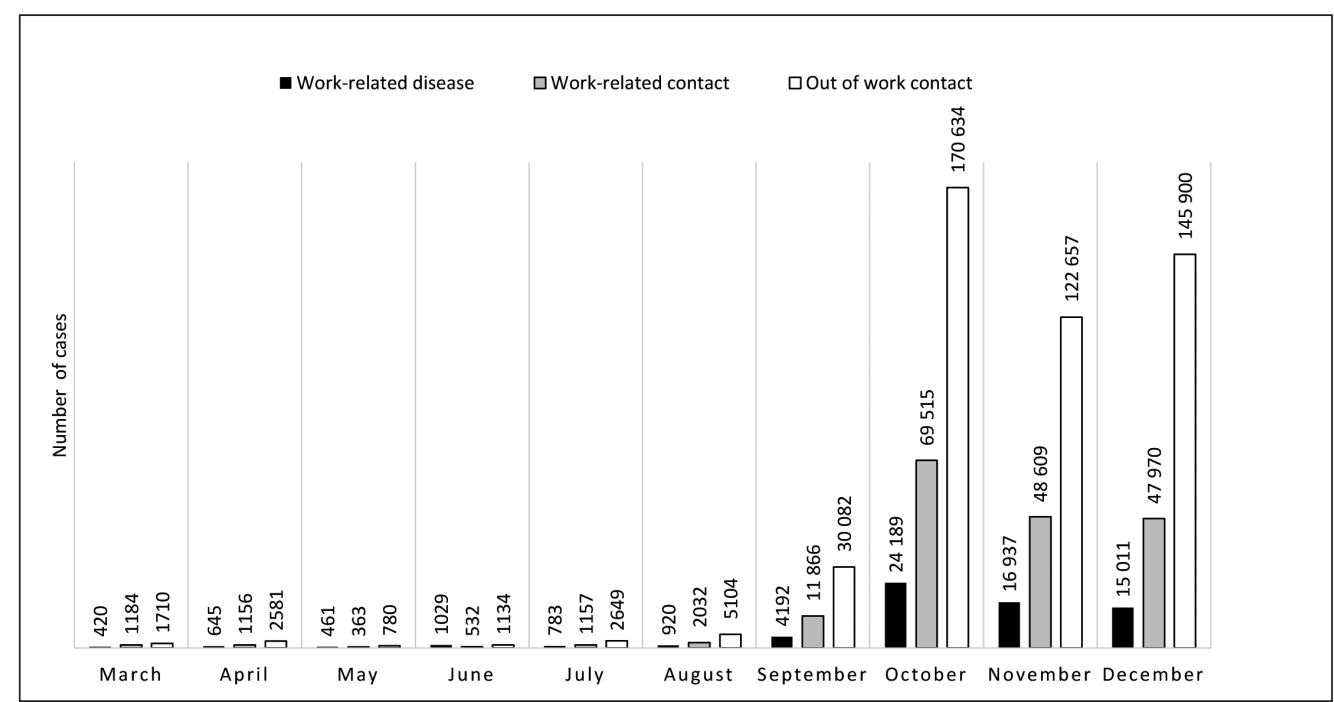

Fig. 1. Dg. COVID-19 (732,202 cases) according to probable exposure in the period March-December 2020 (Source: ÚZIS Prague).

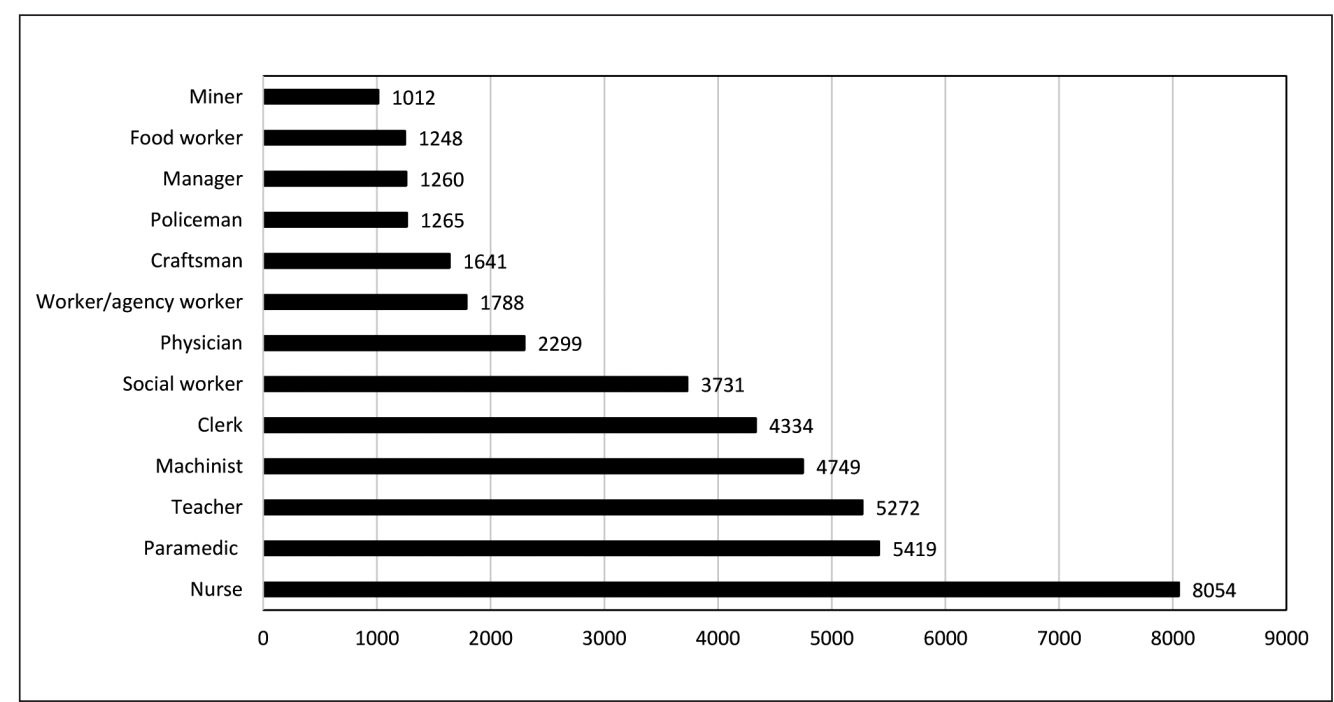

Fig. 2. Dg. COVID-19 (42,072 cases) signed as work-related disease in selected occupations/professions in the period MarchDecember 2020 (Source: ÚZIS Prague). 
to obtain valid information about the transmission of an infectious agent in a specific environment, e.g., at work or out of work, during school lessons or out of school, in or outside a shop, in or out of transport. The probability of transmission of infectious agents is modified by its dose, climatic conditions, indoor stay, ventilation, introduction or release of restrictions, presence at work or outside, means of transport, and other factors that are difficult to predict. The possibility of transmitting the pathogen (coronavirus) during the work is considered one of the most important, although precise data are still not available. It is quite logical to expect that health and social workers are most at risk in this regard.

The possibility of coronavirus transmission/exposure during work is considered significant. In the analysed period, especially from the autumn months 2020, during the community spread of the disease, the out-of-work origin of the disease prevailed but the relation to work was recorded in about a third of cases.

The probable exposure to the pathogen in the 13 most affected occupations is shown in Figure 2 (42,072 cases). However, it is not possible to estimate the risk of infection for individual occupations from the absolute numbers of diseases due to the different numbers of persons in these occupations. The probable onset of illness related to occupational exposure was recorded in $64,587(9 \%)$ of cases, of which only a small part - $150(0.2 \%)$ has so far been recognized as an occupational disease; however, this number is increasing very rapidly during 2021 . The process of recognition of occupational diseases and their entry into the statistics has some delays, so a significant proportion of cases of occupational diseases detected in 2020 will be part of the 2021 statistics. An occupational disease is defined in the Czech Republic as a disease caused by the noxious effects of chemical, physical, biological, and other factors, provided that the disease originated under conditions described in the List of Occupational Diseases. For the recognition of COVID-19 as an occupational disease according to current legislation, the following conditions must be met: clinically manifested disease confirmed by laboratory examination and hygienic investigation of work conditions described in the List of Occupational Diseases (Government Regulation No. 290/90 Coll., Chapter V, Items 1 and 3). Verification of work conditions (hygienic criteria) is associated with so called risk of infection. In this context, the risk of infection means a higher probability of transmission of infectious agent (coronavirus) during the actual performance of work activities than during the usual performance of work and normal contact with other persons, even during the epidemic occurrence of the disease. Proof that the disease actually arose in direct causal connection with the performance of work (e.g., contact with a specific person) is not necessary (5). The fulfilment of the conditions for the occurrence of an occupational COVID-19 is assumed in particular for healthcare professionals, workers in social service facilities, members of the police, army, fire brigade, where the transmission of infection in risky contact with a person during the performance of their work cannot be completely ruled out, in contrast to other occupations (administrative work, sales of goods, manufacturing plants, where compliance with applicable antiepidemic measures is not expected) to be more likely to spread the infectious agent (coronavirus) than in the general population. The European Union of Medical Specialists (UEMS) Section of Occupational Medicine as the body representing national associations of medical specialists published Statement on COVID-19 as occupational disease based on sufficient occupational exposure through taking the occupational history, results of epidemiological circumstances at the workplace and exposure. COVID-19 can be recognized as occupational disease in any sector at any workplace where work tasks are necessarily associated to close contacts with (potentially) COVID-19 patients and/or COVID positive contacts. COVID-19 should be recognized as occupational disease where there is increased risk for COVID-19 infection in working process, however, this risk should be taken into account individually case by case (higher epidemiological risk than in general population). Personal protective equipment does not exclude COVID 19 to be recognized as occupational disease (6).

\section{CONCLUSIONS}

The current course of the COVID-19 epidemic in the Czech Republic is characterized by significant fluctuations in the incidence of the disease and in the spread of the disease, from the initial decline in the spread of the disease through community spread without the possibility of effective contact search to the present gradual decline of the epidemic. The available data show probable exposures to an infectious agent (without proof of specific contact with the source of the infection), of which at least one third are related to work, so different relevant anti-epidemic measures in the workplace have considerable practical importance for epidemic control.

\section{Acknowledgements}

Author expresses acknowledge Jan Žofka, Institute of Health Information and Statistics of the Czech Republic, Prague, Czech Republic, for help with data clarification and interpretation. The study was supported by the programme PROGRES Q25/LF1, Charles University, Prague.

\section{Conflict of Interests}

None declared

\section{REFERENCES}

1. New coronavirus SARS-CoV-2 and disease COVID-19. Farmakoterapeut Rev. 2020;5 Suppl 1:1-97. (In Czech.)

2. Ministry of Health [Internet]. Prague: Ministry of Health of the Czech Republic; 2021 [cited 2021 May 17]. Covid-19 epidemic in the Czech Republic. Available from: https://koronavirus.mzcr.cz/en/.

3. Tuček M. COVID-19 as an occupational disease in the Czech Republic. In: ETUI Seminar on Covid-19 as occupational disease. National reports [Internet]. Brussels: ETUI; 11 March 2021 [cited 2021 June 9]. 41-49. Available from: https://www.etui.org/news/covid-19-occupationaldisease-need-european-homogenisation.

4. Occupational diseases in the Czech Republic 2020 [Internet]. Prague: NIPH; 2021 [cited 2021 May 17]. Available from: http://www.szu.cz/ publikace/data/nemoci-z-povolani-a-ohrozeni-nemoci-z-povolani-vceske-republice. (In Czech.)

5. Tuček M, Nakládalová M. COVID-19 as an occupational disease brief information on the situation in the Czech Republic. Cas Lek Ces. 2020;159(3-4):157. (In Czech.)

6. UEMS Occupational Medicine Statement on COVID-19 as occupational disease [Internet]. Brussels: UEMS; 2021 [cited 2021 May 17]. Available from: https://uems-occupationalmedicine.org/covid-19-as-occupationaldisease/. 